\title{
Recordando para valorar y celebrar quince meritorios años
}

\author{
Alberto Enrique D’OTTAVIO CATTANI
}

\section{Remembering to celebrate and prize fifteen praiseworthy years}

\author{
Facultad de Ciencias Médicas y Consejo de Investigaciones. Universidad Nacional de Rosario (Argentina). \\ Autor para correspondencia: Alberto Enrique D’Ottavio. Correo electrónico: aedottavio@hotmail.com \\ Recibido el 24 de mayo de 2019; aceptado el 1 de junio de 2019.
}

Cómo citar este artículo: D’Ottavio Cattani AE. Recordando para valorar y celebrar quince meritorios años. Rev Med Cine [Internet] 2019;15(3):135-136. DOI: http://dx.doi.org/10.14201/rmc2019153135136

Rondaría los diez años de edad cuando en una colección de libros que se publicaba en mi país ${ }^{1}$, me cautivó la vida de Louis Pasteur y su lucha contra la rabia, enfermedad crudelísima si es que pudiere hacerse un orden de prelación de tales patologías.

Aunque por entonces ya había decidido estudiar Medicina, ello me reafirmó en esa convicción ignorando, sin embargo, que de algún modo anticipaba también mi ulterior dedicación exclusiva a la docencia y a la investigación científica.

Pocos años después, el conmovedor y apoteósico final del filme "La tragedia de Louis Pasteur" (The story of Louis Pasteur) ${ }^{2}$, me urgiría vanamente por ingresar a la facultad porque, en realidad, distaba de haber concluido el ciclo secundario.

Con el tiempo colegí que aquellos libros y esas películas, gozadas durante mi infancia y pubertad, habían tenido significativa influencia no sólo en mi decisión por la carrera médica sino en el derrotero académico que prosigo transitando.

Este recuerdo de senectud destaca la singular relevancia que el cine y la literatura, de mutua interacción e íntima ligazón, pueden llegar a tener en elecciones determinantes del futuro modo y medio de vida personales.

En ese contexto, resulta notoria la conmemoración y celebración del más que merecido decimoquinto aniversario de la Revista de Medicina y Cine, cuyo impacto excede largamente su potencial influencia en la juvenil orientación pre-profesional (la sempiterna vocación) al brindar, asimismo, material motivacional para la enseñanza de grado en todas las vertientes de la salud, y proveer un modo alternativo de acercamiento al ser humano como entidad perfectible preñada de luces y sombras, riquezas y pobrezas, grandezas y miserias.

Ejemplo digno de emulación por otras profesiones, esta publicación ha contribuido y contribuye, además, al enriquecimiento humanístico de alumnos y egresados del área de la salud en línea con el reiterado aforismo de Don José de Letamendi y Manjarrés: "Quien solo de Medicina sabe, ni de Medicina sabe"3,4, que conlleva la exigencia para ellos de adquirir una cultura tal que, entre otros, amplifique el espacio operativo de la profesión, les permita adaptarse a los distintos niveles educativos de los interlocutores, y sea capaz de diluir o anular cualquier atisbo improcedente de soberbia.

En suma, motivación, incentivación, orientación, información y formación, en un marco de seria y fundamentada amenidad, son inapelables aportaciones de esta iniciativa fraternal, respaldada por una Universidad de los quilates de la de Salamanca, que desde hace tres lustros, cuatro veces cada año, sorprende y gratifica a sus lectores rescatando filmes olvidados, presentando otros desconocidos y proveyendo enfoques variados de algunos repetidos.

Puede que un adecuado colofón para este acontecimiento sea decir que la Revista de Medicina y Cine es 
un claro ejemplo de lo que se consigue cuando, si bien pasible es recurrir al auxilio de terceros, nada mejor existe que trabajar como si todo dependiera exclusivamente del esfuerzo propio.

\section{Referencias}

1. Cruz C. Pasteur. Buenos Aires: Editorial Atlántida; 1941.

2. IMDb. The story of Louis Pasteur (1936) [Internet ] [Consultado el 23 de mayo de 2019].

3. D'Ottavio AE. 10을 Aniversario de la Revista de Medicina y Cine: una perdurable y fructífera iniciativa educadora. Rev Med Cine [Internet] 2014; 10(2): 55-6.

4. D'Ottavio AE, García Sánchez JE, García Sánchez E. The cinema as a fostering tool for health area undergraduates. Rev Med Cine [Internet] 2019; 15(2): 101-5.

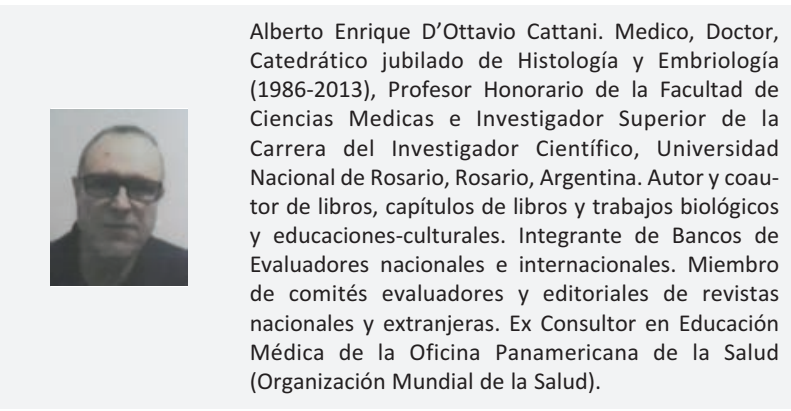

